\title{
Clinical Manifestations, Antimicrobial Drug Susceptibility Patterns, and Outcomes in Melioidosis Cases, India
}

\section{Maria Koshy, Manjeera Jagannati, Ravikar Ralph, Punitha Victor, Thambu David, Sowmya Sathyendra, Balaji Veeraraghavan, George M. Varghese}

We studied the clinical manifestations and outcomes of 114 patients with culture-confirmed melioidosis treated at a tertiary hospital in southern India. Diabetes mellitus is the main risk factor, and chronic melioidosis mimicking tuberculosis was more common than acute disease. Septicemia and respiratory involvement were associated with poor outcomes.

$\mathrm{M}$ elioidosis is a tropical infection caused by the environmental bacterium Burkholderia pseudomallei (1). The clinical spectrum of melioidosis ranges from the acute septicemic form, which is often fulminant, to chronic disease, which mimics other common infections like tuberculosis (2). Melioidosis is endemic to southeast Asia and northern Australia; seasonal peaks occur during monsoons (3). Infection is acquired by inhalation, inoculation, and ingestion (4).

Melioidosis is often difficult to diagnose because of diverse clinical manifestations, low index of suspicion, and poor availability of good laboratory facilities. Hence, the disease remains underrecognized even in endemic countries. Recent studies have shown that India is at high risk for a surge of cases of melioidosis (5). Our study was undertaken to delineate the clinical manifestations, antimicrobial drug susceptibility patterns, and outcomes of melioidosis cases in India.

\section{The Study}

This retrospective study included 114 adult patients with culture-confirmed melioidosis treated at a tertiary care teaching hospital in southern India during January 2008December 2014. We collected data regarding patient demographics, clinical characteristics, laboratory results, radiologic parameters, and antimicrobial drug susceptibility from medical records. We classified patients on the basis of duration of symptoms: acute ( $<2$ months) or chronic ( $>2$ months) (6). We defined multifocal disease as involvement

Author affiliation: Christian Medical College, Vellore, India

DOI: https://doi.org/10.3201/eid2502.170745 of $\geq 2$ organs and disseminated disease as involvement of 1 organ plus bacteremia (7). We assessed severity of illness (based on sequential organ failure assessment [SOFA] scores), complications, and patient outcomes (8). We used the BacT ALERT (bioMérieux, https://www.biomerieux. com) automated system for blood culture. We plated pus and tissue on blood, chocolate, and MacConkey agar and identified B. pseudomallei according to standard methods and performed antimicrobial drug susceptibility testing according to Clinical and Laboratory Standards Institute standards using E-test for trimethoprim/sulfamethoxazole. We summarized descriptive data and analyzed the association of patient parameters with outcomes by using logistic regression. We considered a 2 -sided $\mathrm{p}$ value of $\leq 0.05$ statistically significant. We analyzed the data using SPSS Statistics for Windows version 20.0 (IBM, https://www.ibm.com).

Patients were predominantly male (92\%); mean age was 45.6 years (33.5-57.7 years). The patients came from 15 states in India; most were from West Bengal (26.3\%), Jharkhand (22.8\%), and Tamil Nadu (14.9\%) (Figure 1). The common risk factors identified were diabetes mellitus $(81.6 \%)$, harmful ethanol consumption (14\%), and chronic kidney disease $(3.5 \%)$. Among patients with diabetes, glycemic control was poor (mean hemoglobin A1c 9.7\% $[7.1 \%-12.3 \%])$. Other risk factors included sickle cell disease, thalassemia, glucocorticoid use, and liver disease (Table 1). Patients with acute disease more commonly sought care $(80.5 \%, \mathrm{n}=33)$ during the cooler months of August-February.

Chronic melioidosis was more common than acute melioidosis $(64 \%$ vs. $36 \%)$ in this patient cohort. Duration of symptoms was 2 days to 5 years (median 60 days; interquartile range [IQR] 30-90 days). Fever was the most consistent symptom $(97.2 \%)$. Although other studies have reported lung involvement to be most common (9), we most frequently observed splenic (42.9\%) and musculoskeletal (37.7\%) disease (Table 1). Chronic melioidosis was associated with splenic and genitourinary involvement. Prostatic abscess was the most common genitourinary disease $(87.5 \%, \mathrm{n}=12)$. Multifocal disease was evident in $89(78 \%)$ patients. Two patients had tuberculosis-melioidosis co-infection and improved with appropriate therapy for both diseases. 


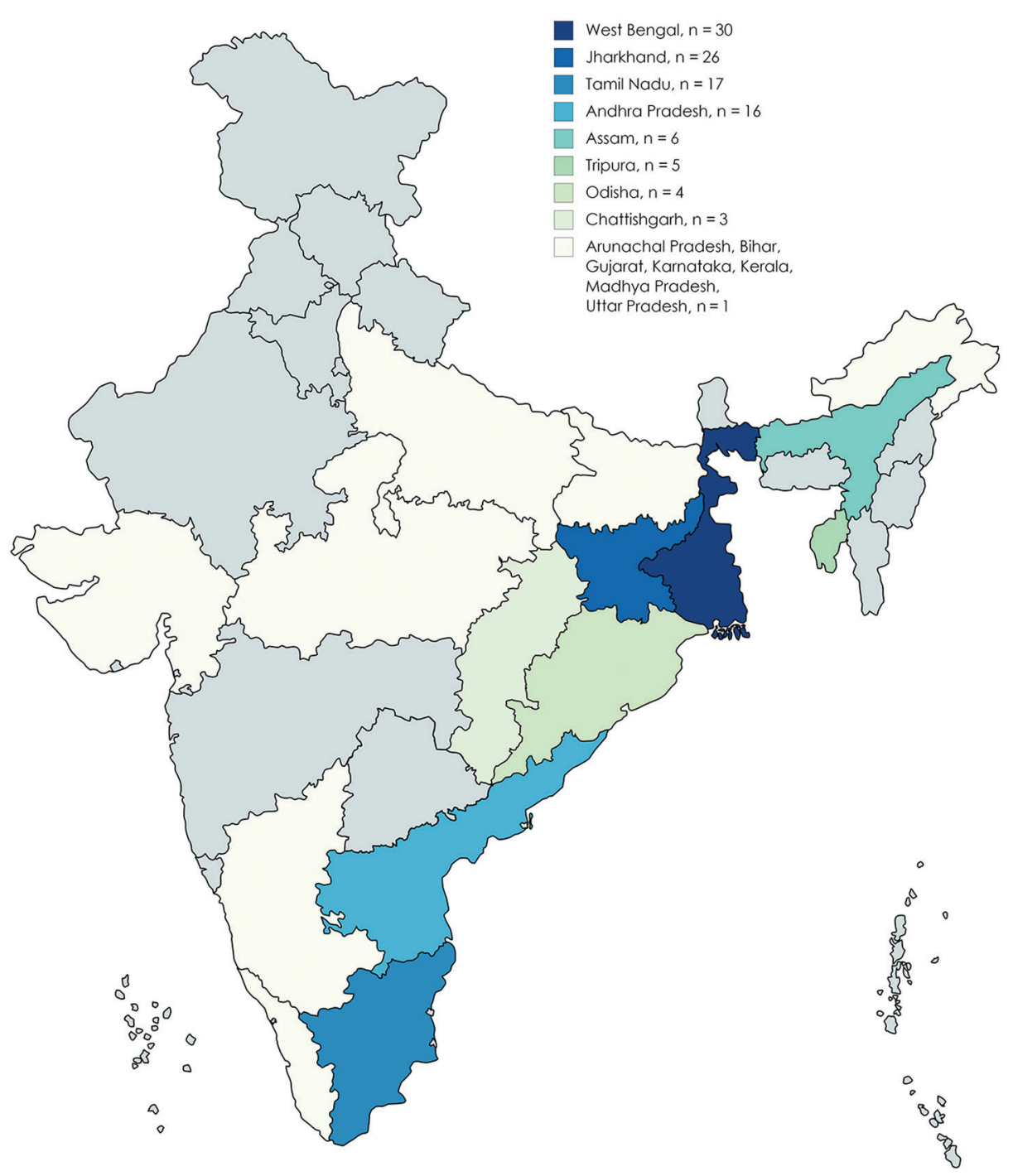

Figure 1. Distribution of patients with melioidosis, by state, India, 2008-2014.
Chest radiograph abnormalities included bilateral fluffy opacities $(16.7 \%, \mathrm{n}=19)$, focal infiltrates $(6.1 \%, \mathrm{n}=7)$, and effusions $(6.1 \%, \mathrm{n}=7)$.

Patients with acute melioidosis frequently had respiratory involvement and bacteremia. Septic arthritis was common in acute disease and usually involved a single large joint. One patient had evidence of multifocal arthritis. Three patients had central nervous system involvement. Five patients had bacteremia without evidence of deep-seated abscesses. We also observed unusual presentations, such as pancreatitis and pericardial involvement. In 11 (15.1\%) patients with chronic melioidosis, the condition worsened because of bacteremia and systemic inflammatory response syndrome. This phenomenon occurred especially in elderly patients and patients with diabetes and was associated with higher case-fatality rates.

A total of $63(55.2 \%)$ patients had bacteremia, and $25(21.9 \%)$ patients required admission to intensive care.
Seventy-six $(66.6 \%)$ patients required a diagnostic or therapeutic interventional procedure. Antimicrobial drug susceptibility tests revealed $100 \%$ sensitivity to carbapenems and ceftazidime. Resistance to trimethoprim/sulfamethoxazole was noted in $5.9 \%$ and resistance to doxycycline in $2.6 \%$ of cases.

Patients received intensive therapy with meropenem or ceftazidime for a median duration of 16 days (IQR 14-28 days), followed by eradication therapy with trimethoprim/ sulfamethoxazole with or without doxycycline for a median of 90 days (IQR $90-150$ days). Most patients were treated successfully with these regimens. Follow-up data were available for $57.9 \%$ patients for a period of 3 months to 1 year. Four $(3.5 \%)$ patients had disease recurrence $2-7$ years after completion of therapy, of whom 1 received inadequate therapy. A previous study highlighted that multifocal disease, bacteremia, and duration of therapy correlate with risk for relapse (6). 
Table 1. Patient characteristics and outcomes of patients with melioidosis, southern India, 2008-2014*

\begin{tabular}{|c|c|c|c|}
\hline Characteristic & All patients, $\mathrm{N}=114$ & $\begin{array}{c}\text { Acute melioidosis, } \\
\mathrm{n}=41\end{array}$ & $\begin{array}{c}\text { Chronic melioidosis, } \\
n=73\end{array}$ \\
\hline $\begin{array}{l}\text { Age, y, mean } \pm \text { SD } \\
\text { Sex, no., M/F }\end{array}$ & $\begin{array}{c}45.6 \pm 12.1 \\
105 / 9\end{array}$ & $46 \pm \frac{12.6}{38 / 3}$ & $\begin{array}{c}45.3 \pm 11.9 \\
67 / 6\end{array}$ \\
\hline \multicolumn{4}{|l|}{ Comorbid conditions, no. (\%) } \\
\hline Diabetes mellitus & $93(81.6)$ & $36(87.8)$ & $57(78.1)$ \\
\hline Harmful ethanol use & $16(14)$ & $10(24.4)$ & $6(8.5)$ \\
\hline Chronic kidney disease & $4(3.5)$ & $2(4.9)$ & $2(2.8)$ \\
\hline Sickle cell disease & $3(2.6)$ & 0 & $3(4.2)$ \\
\hline No risk factors & $15(13.2)$ & $3(7.3)$ & $12(16.4)$ \\
\hline Duration of symptoms, d, median (IQR) & $60(30-90)$ & $20(7-30)$ & $90(60-210)$ \\
\hline \multicolumn{4}{|l|}{ Clinical symptoms, no. (\%) } \\
\hline Fever & $105(97.2)$ & $41(100)$ & $64(95.5)$ \\
\hline Cough & $17(15.5)$ & $9(21.9)$ & $8(11.7)$ \\
\hline Abdominal pain & $38(34.8)$ & $10(24.3)$ & $28(41.1)$ \\
\hline Joint pain & $27(24.7)$ & $10(24.3)$ & $17(25)$ \\
\hline Breathlessness & $16(14.6)$ & $11(26.8)$ & $5(7.3)$ \\
\hline \multicolumn{4}{|l|}{ Clinical signs, no. (\%) } \\
\hline Tachypnea, reference $>24 / \mathrm{min}$ & $24(21.2)$ & $14(34.1)$ & $10(13.9)$ \\
\hline Tachycardia, reference $>100 / \mathrm{min}$ & $33(29.2)$ & $20(48.8)$ & $13(18.1)$ \\
\hline Hypotension, reference $<90 / 60 \mathrm{~mm} \mathrm{Hg}$ & $11(9.7)$ & $6(14.6)$ & $5(6.9)$ \\
\hline \multicolumn{4}{|l|}{ Laboratory parameters } \\
\hline Hemoglobin, $\mathrm{g} / \mathrm{dL}$, mean $\pm \mathrm{SD}$ & $10.2 \pm 2.3$ & $11.3 \pm 2.5$ & $9.6 \pm 2$ \\
\hline Lymphocyte count, $\times 10^{9}$ cells/L, median (IQR) & $10.5(7 . \overline{7}-15.4)$ & $14.6(11.1-19.4)$ & $9(6.8-12.2)$ \\
\hline Platelet count, x 10\% $/ \mathrm{L}$, median (IQR) & $165(107-272)$ & $177(115-264)$ & $158(102-280)$ \\
\hline Total bilirubin, mg/dl, median (IQR) & $0.7(0.5-1.4)$ & $1.2(0.7-1.8)$ & $0.6(0.4-0.9)$ \\
\hline Total protein, $\mathrm{g} / \mathrm{dL}$, mean $\pm \mathrm{SD}$ & $7.2 \pm 1$ & $6.7 \pm 0.8$ & $7.5 \pm 1$ \\
\hline Albumin, g/dL, mean $\pm \mathrm{SD}^{-}$ & $2.9 \pm 0.8$ & $2.6 \pm 0.7$ & $3.1 \pm 0.7$ \\
\hline AST, IU/mL, median (IQR) & $42(2 \overline{5}-85)$ & $48(2 \overline{6}-128)$ & $36(24-83)$ \\
\hline ALT, IU/mL, median (IQR) & $29(15-60)$ & $28(13-99)$ & $30(15-56)$ \\
\hline ALP, IU/mL, median (IQR) & $148(85-249)$ & $157(102-239)$ & $137(83-276)$ \\
\hline Serum creatinine, $\mathrm{mg} / \mathrm{dL}$, median (IQR) & $1(0.8-1.3)$ & $1.1(0.8-1.3)$ & $1(0.8-1.2)$ \\
\hline Hemoglobin A1C, \%, mean \pm SD & $9.7 \pm 2.6$ & $11.1 \pm 2.9$ & $8.9 \pm 2$ \\
\hline $\mathrm{CRP}, \mathrm{mg} / \mathrm{L}, \mathrm{mean} \pm \mathrm{SD}$ & $96.6 \pm 64.3$ & $152.7 \pm 57.2$ & $77.4 \pm 55.2$ \\
\hline \multicolumn{4}{|l|}{ Organ involvement } \\
\hline Lung & $28(24.5)$ & $16(39)$ & $12(16.4)$ \\
\hline Bacteremia & $63(55.2)$ & $33(80.4)$ & $30(41)$ \\
\hline Spleen & 49 (42.9) & $12(29.2)$ & $37(50.6)$ \\
\hline Liver & $25(21.9)$ & $9(21.9)$ & $16(21.9)$ \\
\hline Genitourinary & $16(14)$ & $2(4.8)$ & $14(19.1)$ \\
\hline Septic arthritis & $22(19.2)$ & $9(21.9)$ & $13(17.8)$ \\
\hline Osteomyelitis & $12(10.5)$ & $3(7.3)$ & $9(12.3)$ \\
\hline Skin and subcutaneous tissue & $15(13.1)$ & $7(17)$ & $8(10.9)$ \\
\hline Parotid & $2(1.7)$ & $2(4.8)$ & 0 \\
\hline Central nervous system & $3(2.6)$ & $2(4.8)$ & $1(1.3)$ \\
\hline Sequential organ failure assessment score, median (IQR) & $2(1-4)$ & $3(1-6)$ & $1(0-3)$ \\
\hline ICU admission, no. (\%) & $25(21.9)$ & $15(36.6)$ & $10(13.7)$ \\
\hline Mechanical ventilation, no. (\%) & $21(18.4)$ & $13(31.7)$ & $8(11)$ \\
\hline Duration of hospitalization, days, median (IQR) & $16.5(9-24)$ & $18(8.5-30.5)$ & $16(10-21.5)$ \\
\hline Case-fatality rate, no. $(\%)$ & $17(14.9)$ & $7(17.1)$ & $10(13.7)$ \\
\hline
\end{tabular}

The overall case-fatality rate was $14.9 \%(n=17)$ and was higher in patients with acute disease (Table 2). On multivariate analysis of predictors of mortality risk, respiratory involvement (odds ratio [OR] 4.61 [95\% CI $1.57-13.55] ; \mathrm{p}=0.005)$ and bacteremia (OR $17.02[95 \%$ CI 2.17-133.43]; $\mathrm{p}=0.007$ ) were independent predictors of mortality, along with admission SOFA scores (OR 1.4 [95\% CI 1.1-1.7]; $\mathrm{p}<0.001)$ and hypoalbuminemia (OR 4.02 [95\% CI 1.21-13.33]; $\mathrm{p}=0.02$ ). We noticed a decline in case-fatality rate from $2008(25 \%)$ to 2014 (11\%) (Figure 2).

\section{Conclusions}

This study highlights the emergence of melioidosis as a major problem in India. Two thirds of our patient population were from the eastern and northeastern parts of India, which might reflect a referral bias. Infection frequently affected the middle-aged, male working population, highlighting possible occupational exposure. The association of acute melioidosis with the wet season in certain regions concurs with other studies that have shown a correlation between rainfall intensity and disease (10). The higher proportion of patients with diabetes $(82.3 \%)$, compared 
Table 2. Bivariate analysis of predictors of mortality from melioidosis, southern India, 2008-2014

\begin{tabular}{|c|c|c|c|c|}
\hline Predictors of mortality & Alive, $\mathrm{n}=97$ & Dead, $\mathrm{n}=17$ & Odds ratio $(95 \% \mathrm{Cl})$ & $\mathrm{p}$ value \\
\hline Diabetes mellitus & 79 & 14 & $0.94(0.23-3.62)$ & 0.92 \\
\hline Harmful ethanol use & 14 & 2 & $0.90(0.18-4.43)$ & 0.89 \\
\hline Chronic kidney disease & 3 & 1 & $0.45(0.04-4.65)$ & 0.5 \\
\hline Tachypnea, reference $>24 / \mathrm{min}$ & 12 & 12 & $16.8(5.03-53.11)$ & $<0.001$ \\
\hline Tachycardia, reference $>100 / \mathrm{min}$ & 22 & 11 & $6.16(2.04-18.57)$ & 0.001 \\
\hline Hypotension, reference $<90 / 60 \mathrm{mmHg}$ & 4 & 7 & $16.10(4.00-64.70)$ & $<0.001$ \\
\hline Sequential organ failure assessment score & $1(0-3)$ & $4(2-8)$ & $1.4(1.1-1.7)$ & $<0.001$ \\
\hline Bacteremia & 47 & 16 & $17.02(2.17-133.43)$ & 0.007 \\
\hline Respiratory involvement & 19 & 9 & $4.61(1.57-13.55)$ & 0.005 \\
\hline Hypoalbuminemia, reference $<3 \mathrm{~g} / \mathrm{dL}$ & 38 & 13 & $4.02(1.21-13.33)$ & 0.02 \\
\hline Intensive care unit admission & 12 & 13 & $23.02(6.44-82.24)$ & $<0.001$ \\
\hline Mechanical ventilation & 8 & 13 & $36.15(9.52-137.23)$ & $<0.001$ \\
\hline
\end{tabular}

to other studies $(39 \%-60 \%)$, might reflect the emerging diabetes epidemic in India $(4,11)$.

The predominance of chronic melioidosis is a finding not in keeping with other studies $(1,4,10)$ and might be attributed in part to referral bias and referral of undiagnosed cases from relatively dry areas of the country. Patients with acute disease tended to reside near our hospital. The occurrence of an acute worsening in patients with chronic disease was associated with a poor outcome. The observation of tuberculosis-melioidosis co-infection is not unusual given that the risk factors and interferon-mediated host response is common to both conditions (12).

Most patients were treated successfully with intensive therapy followed by eradicative therapy. The case-fatality rate associated with melioidosis was $14.9 \%$, with a decreasing trend over the study period. A study previously conducted from this hospital reported a case-fatality rate of $17 \%(7)$, which is lower than the case-fatality rate in Thailand $(\approx 40 \%)$ (13). We found that bacteremia, respiratory involvement, hypoalbuminemia, and high SOFA scores were associated with poor outcomes.

We found that $5.9 \%$ of $B$. pseudomallei isolates were resistant to trimethoprim/sulfamethoxazole. This percentage might have been a slight overestimate because of the change in antimicrobial drug susceptibility testing methods during the study period. Although a previously reported trial showed noninferiority of trimethoprim/ sulfamethoxazole to trimethoprim/sulfamethoxazole plus doxycycline, eradication therapy in our clinical setting should be based on antimicrobial drug susceptibility reports (14).

Melioidosis warrants attention from clinicians and public health officials in India. Specific organ involvement can alert clinicians to acute or chronic disease, which might be useful in management of patients in a resource-limited setting. Because of the substantial mortality associated with melioidosis, a high index of suspicion and early initiation of therapy are essential.

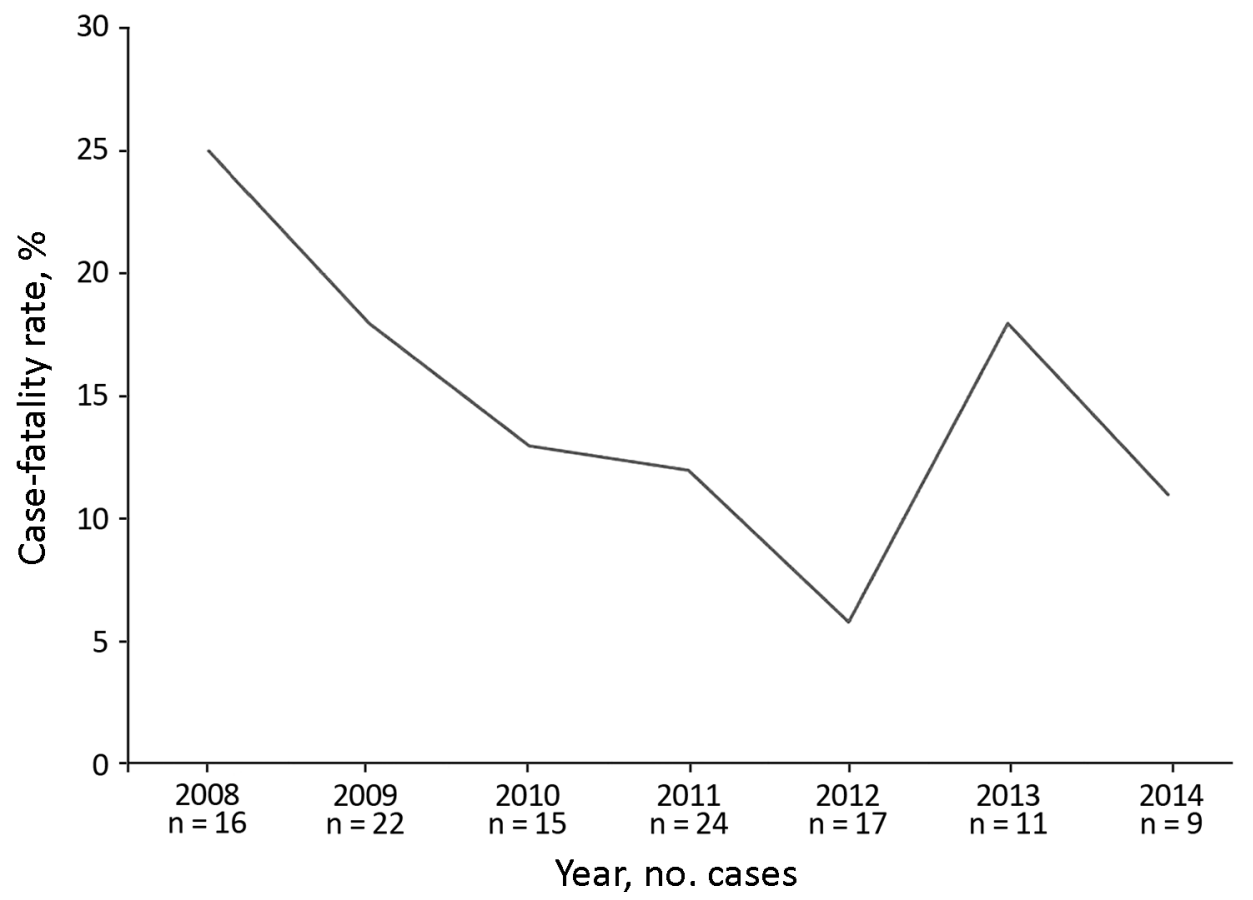

Figure 2. Trend in melioidosis case-fatality rates, southern India, 2008-2014. 


\section{About the Author}

Dr. Varghese is a professor of infectious diseases at Christian Medical College, Vellore, India. His research includes the epidemiology, pathogenesis, early recognition, and management of rickettsial infections, particularly scrub typhus, apart from tropical infections such as melioidosis.

\section{References}

1. Wiersinga WJ, Currie BJ, Peacock SJ. Melioidosis. N Engl J Med. 2012;367:1035-44. http://dx.doi.org/10.1056/NEJMra1204699

2. Dance DAB. Melioidosis. Curr Opin Infect Dis. 2002;15:127-32. http://dx.doi.org/10.1097/00001432-200204000-00005

3. Cheng AC, Currie BJ. Melioidosis: epidemiology, pathophysiology, and management. Clin Microbiol Rev. 2005;18:383-416. http://dx.doi.org/10.1128/CMR.18.2.383-416.2005

4. Currie BJ, Ward L, Cheng AC. The epidemiology and clinical spectrum of melioidosis: 540 cases from the 20 year Darwin prospective study. PLoS Negl Trop Dis. 2010;4:e900. http://dx.doi.org/10.1371/journal.pntd.0000900

5. Limmathurotsakul D, Golding N, Dance DA, Messina JP, Pigott DM, Moyes CL, et al. Predicted global distribution of Burkholderia pseudomallei and burden of melioidosis. Nat Microbiol. 2016;1:15008. http://dx.doi.org/10.1038/nmicrobiol.2015.8

6. Currie BJ, Fisher DA, Anstey NM, Jacups SP. Melioidosis: acute and chronic disease, relapse and re-activation. Trans R Soc Trop Med Hyg. 2000;94:301-4. http://dx.doi.org/10.1016/ S0035-9203(00)90333-X

7. Chrispal A, Rajan SJ, Sathyendra S. The clinical profile and predictors of mortality in patients with melioidosis in South India. Trop Doct. 2010;40:36-8. http://dx.doi.org/10.1258/td.2009.090093

8. Ferreira FL, Bota DP, Bross A, Mélot C, Vincent JL. Serial evaluation of the SOFA score to predict outcome in critically ill patients. JAMA. 2001;286:1754-8. http://dx.doi.org/10.1001/jama.286.14.1754

9. Currie BJ, Fisher DA, Howard DM, Burrow JN, Lo D,

Selva-Nayagam S, et al. Endemic melioidosis in tropical northern Australia: a 10-year prospective study and review of the literature. Clin Infect Dis. 2000;31:981-6. http://dx.doi.org/10.1086/318116

10. Vidyalakshmi K, Lipika S, Vishal S, Damodar S, Chakrapani M. Emerging clinico-epidemiological trends in melioidosis: analysis of 95 cases from western coastal India. Int J Infect Dis. 2012;16:e491-7. http://dx.doi.org/10.1016/j.ijid.2012.02.012

11. Suputtamongkol Y, Chaowagul W, Chetchotisakd P,

Lertpatanasuwun N, Intaranongpai S, Ruchutrakool T, et al. Risk factors for melioidosis and bacteremic melioidosis. Clin Infect Dis. 1999;29:408-13. http://dx.doi.org/10.1086/520223

12. Koh GCKW, Schreiber MF, Bautista R, Maude RR, Dunachie S, Limmathurotsakul D, et al. Host responses to melioidosis and tuberculosis are both dominated by interferon-mediated signaling. PLoS One. 2013;8:e54961. http://dx.doi.org/10.1371/ journal.pone. 0054961

13. Limmathurotsakul D, Peacock SJ. Melioidosis: a clinical overview. Br Med Bull. 2011;99:125-39. http://dx.doi.org/10.1093/bmb/ldr007

14. Chetchotisakd P, Chierakul W, Chaowagul W, Anunnatsiri S, Phimda K, Mootsikapun P, et al. Trimethoprim-sulfamethoxazole versus trimethoprim-sulfamethoxazole plus doxycycline as oral eradicative treatment for melioidosis (MERTH): a multicentre, double-blind, non-inferiority, randomised controlled trial Lancet. 2014;383:807-14. http://dx.doi.org/10.1016/ S0140-6736(13)61951-0

Address for correspondence: George M. Varghese, Christian Medical College, Department of Infectious Diseases, Ida Scudder Rd, Vellore, Tamil Nadu, 632004, India; email: georgemvarghese@hotmail.com

\section{EID Podcast:}

\section{The Mother of All Pandemics}

Dr. David Morens, of the National Institute of Allergy and Infectious Diseases, discusses the 1918 influenza pandemic.

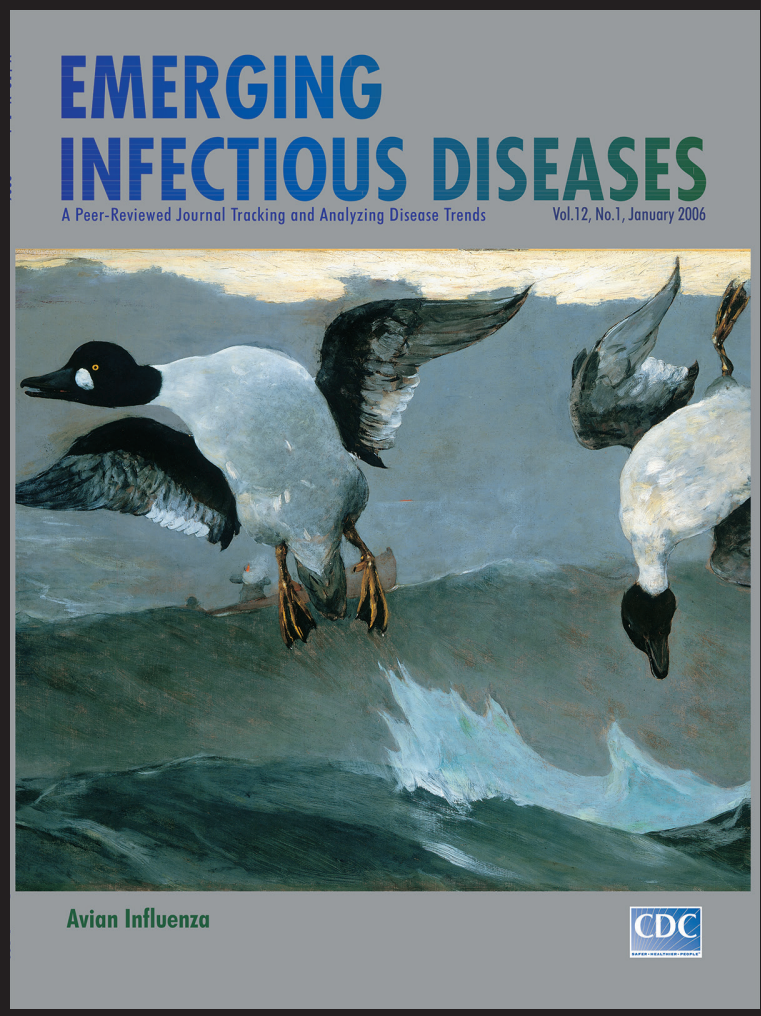

Visit our website to listen: https://tools.cdc.gov/medialibrary/ index.aspx\#/media/id/393805 EMERCINC WNFECTIOUS DISEASES 